\title{
Impact of Hand Hygiene on Hospital-Acquired Infection Rate in Neuro Trauma ICU at a Level 1 Trauma Center in the National Capital Region of India
}

\author{
Purva Mathur ${ }^{2}$ \\ ${ }^{1}$ Department of Hospital Administration, Jai Prakash Narayan Apex \\ Trauma Centre, All India Institute of Medical Sciences, New Delhi, \\ India \\ 2Department of Microbiology, Jai Prakash Narayan Apex Trauma \\ Centre, All India Institute of Medical Sciences, New Delhi, India \\ ${ }^{3}$ Infection Control Nurse, Jai Prakash Narayan Apex Trauma Centre, \\ All India Institute of Medical Sciences, New Delhi, India
}

Sandeep Boora ${ }^{1}$ Parul Singh ${ }^{2}$ Roshni Dhakal ${ }^{3} \quad$ Dennis Victor ${ }^{3} \quad$ Jacinta Gunjiyal ${ }^{3} \quad$ Amit Lathwal $^{1}$

\begin{abstract}
Address for correspondence Purva Mathur, MD, Department of Microbiology, Jai Prakash Narayan Apex Trauma Centre, All India Institute of Medical Sciences, 3rd Floor, New Delhi - 110029, India (e-mail: purvamathur@yahoo.co.in).
\end{abstract}

J Lab Physicians 2021;13:148-150.

\begin{abstract}
Introduction Compliance to hand hygiene $(\mathrm{HH})$ is an important measure in preventing infections to patients in health-care settings. Wellness and safety of patients and health-care workers (HCWs) can be achieved by promoting best practices in infection control through education and advocacy.

Aims and Objectives To assess the compliance to $\mathrm{HH}$ among all cadres of HCWs and its association with hospital-acquired infection (HAI) in patients.

Materials and Methods A prospective, observational study was conducted for a period of 5 years (January 2014 to December 2018) in Neuro Trauma intensive care unit. A standard checklist based on World Health Organization's 5 Moments for Hand Hygiene was used as a tool to measure the $\mathrm{HH}$ compliance.

Results HAl rate was found to be directly proportional to the compliance to $\mathrm{HH}$. Reduction in $\mathrm{HAl}$ rates was reported when there was an increase in $\mathrm{HH}$ compliance. $\mathrm{HAI}$ of $4.25 \%$ was found to be lowest in the year 2015 with the compliance to $\mathrm{HH}$ of $63.65 \%$. The HH compliance was also found to be highest (64.63\%) in the year 2016 followed by $64.12 \%$ in the year 2017 . During this period HAI rates were $4.35 \%$ and $4.8 \%$, respec-

Keywords

- hand hygiene

- health care workers

- hospital-acquired infection tively. When the $\mathrm{HH}$ compliance declined in the year 2018 to $53.95 \%$, there was an increase in the rate of $\mathrm{HAl}$ to $6.9 \%$.

Conclusion It could be concluded that $\mathrm{HH}$ compliance was associated with the decrease in HAls. $\mathrm{HH}$ could be a simple and cost-effective method in the prevention of HAls.
\end{abstract}

\section{Introduction}

Compliance to hand hygiene ( $\mathrm{HH})$ is an important measure in preventing infections to patients in health care

published online June 25, 2021
DOI https://doi.org/

$10.1055 / \mathrm{s}-0041-1730820$ ISSN $0974-2727$ settings. Wellness and safety of patients and health care workers (HCWs) can be achieved by promoting best practices in infection control through education and advocacy.

(c) 2021. The Indian Association of Laboratory Physicians.

This is an open access article published by Thieme under the terms of the Creative Commons Attribution-NonDerivative-NonCommercial-License, permitting copying and reproduction so long as the original work is given appropriate credit. Contents may not be used for commercial purposes, or adapted, remixed, transformed or built upon. (https://creativecommons.org/licenses/by-nc-nd/4.0/).

Thieme Medical and Scientific Publishers Pvt. Ltd. A-12, 2nd Floor, Sector 2, Noida-201301 UP, India 
Hospital-acquired infections (HAIs) are considered as undesirable outcome and since they are preventable, they are considered as a quality indicator of patient care.

The impact of HAI may be prolonged hospital stays, long-term disability, increased resistance of microorganisms to antimicrobials, massive additional financial burdens, an excess of deaths, high costs for the health systems, and emotional stress for patients and their families. ${ }^{1}$

Transmission of health care-associated pathogens occurs through direct and indirect contact, droplets, air, and/or some common vehicle. Transmission through contaminated HCWs' hands is a common pattern in most settings. ${ }^{2}$

Many studies have pointed out that HCWs can contaminate their hands or gloves with pathogens while performing "clean procedures" or touching intact areas of skin of hospitalized patients. ${ }^{3,4,5}$

HCWs can also become infected during patient care. ${ }^{6,7}$ In fact, HCWs were infected during the influenza pandemics. ${ }^{1,8}$

$\mathrm{HH}$ has proven to be effective in preventing HAI and the spread of antimicrobial resistance. It has been seen that HCWs find it difficult to comply with $\mathrm{HH}$ indications at different levels. ${ }^{1}$

\section{Aims and Objectives}

To assess the compliance to HH among all cadres of HCWs and its association with HAI in patients.

\section{Materials and Methods}

A prospective, observational study was conducted for a period of 5 years (January 2014 to December 2018) in a 20-bedded neurosurgery intensive care unit (ICU) of the 248-bed AIIMS Trauma Center, a tertiary care patient care, teaching, and research hospital in Delhi, India. A standard checklist based on World Health Organization's (WHO's) 5 Moments for Hand Hygiene was used as a tool to measure the HH compliance. All cadres of HCWs were observed for HH compliance by an infection control nurse posted in the Neuro Trauma ICU by direct observation for a minimum time period of 1 hour per 24 hours. The infection control team held monthly meetings to review the data. A monthly report of data on $\mathrm{HH}$ compliance, interventions, and barriers to implementation were discussed and noted.

\section{Results}

HAI rate was found to be directly proportional to the compliance to HH ( - Fig. 1). Reduction in HAI rates was reported when there was an increase in $\mathrm{HH}$ compliance ( - Fig. 2). HAI of $4.25 \%$ was found to be lowest in the year 2015 with the compliance to $\mathrm{HH}$ of $63.65 \%$ ( - Fig. 3). The HH compliance was also found to be highest (64.63\%) in the year 2016 followed by $64.12 \%$ in the year 2017 ( - Fig. 3). During this period HAI rates were $4.35 \%$ and $4.8 \%$, respectively ( - Fig. 3 ). When the $\mathrm{HH}$ compliance declined in the year 2018 to $53.95 \%$, there was an increase in the rate of HAI to $6.9 \%$ ( - Fig. 3 ).

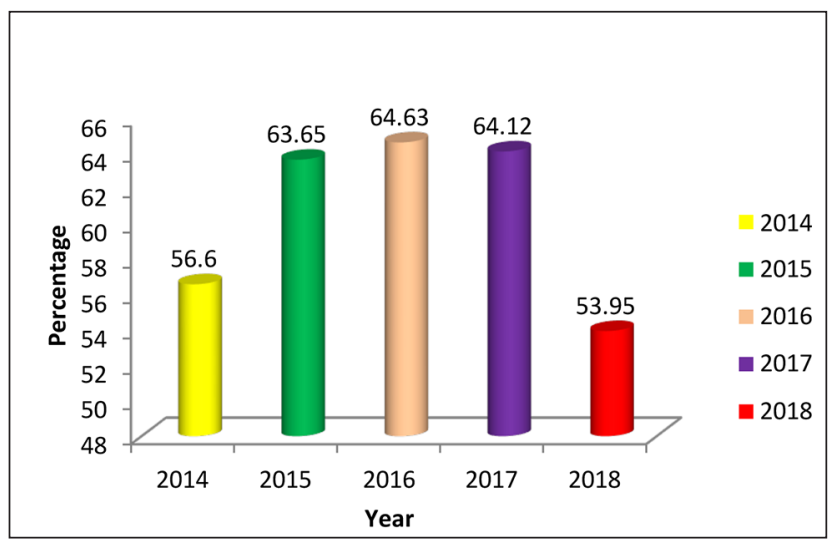

Fig. 1 Hand hygiene compliance (\%).

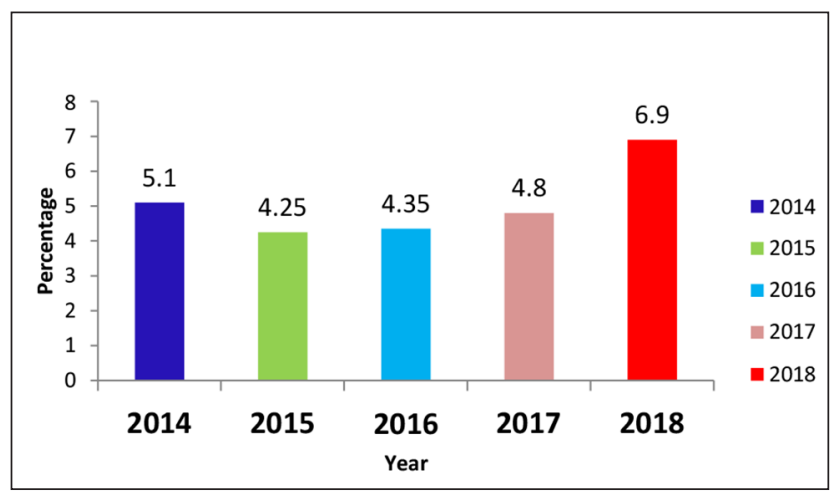

Fig. 2 Hospital-acquired infection (HAI) rate.

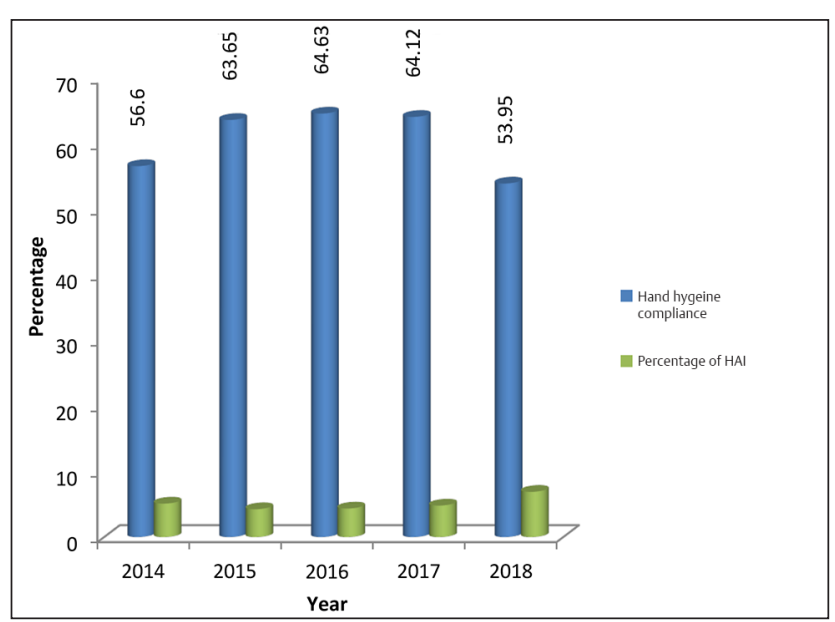

Fig. 3 Percentage of hand hygiene compliance versus hospital-acquired infection ( $\mathrm{HAl}$ ) rates.

\section{Discussion}

Variable compliance rates to $\mathrm{HH}$ have been found in both developed and developing countries. Adherence by HCWs to recommended $\mathrm{HH}$ procedures (with mean baseline rates) ranges from $5 \%$ to $89 \%$, with an overall average of $38.7 \% .{ }^{1} \mathrm{HH}$ compliance among HCWs in an accredited tertiary care hospital as per WHO Guidelines was 78\%. Nurses had an adherence rate of $63 \%$; and the allied staff had an adherence of $86.5 \%{ }^{9}$ 
In an observational study on $\mathrm{HH}$ compliance in ICUs, the mean $\mathrm{HH}$ compliance rates increased from 75.1 to $88.6 \%$ during the study period, yielding an estimated increase of approximately $4.5 \%$ per year. ${ }^{10}$ In another study on $\mathrm{HH}$ compliance in the ICUs of a tertiary care hospital, it was found out that the overall compliance was 43.2\% (301/728) among different HCWs. ${ }^{11}$

About 20 hospital-based studies of the impact of $\mathrm{HH}$ on the risk of HAI, published between 1977 and June 2008, showed a temporal relation between improved HH practices and reduced infection and cross-transmission rates. ${ }^{1}$

In a study on the effect of $\mathrm{HH}$ compliance on HAIs in an ICU setting, the overall rate of HH compliance by all the HCWs increased from $42.9 \%$ preintervention to $61.4 \%$ postintervention. The effect of the increase in the $\mathrm{HH}$ compliance rate on the nosocomial infection rate was noticeable. There were remarkable reductions in the rate of overall health care-associated infections per 1,000 patient-days, from 37.2 preintervention to 15.1 postintervention; the rate of bloodstream infections decreased from 18.6 to 3.4 per 1,000 central-line-days; and the rate of lower respiratory tract infections decreased from 17.6 to 5.2 per 1,000 ventilator days. ${ }^{12}$

As a note of caution, one study points out that it is common to link HH interventions to infection reduction without reporting on other prevention strategies associated with these high-risk exposures. The logic that good HH compliance contributes to the prevention of HAIs can be accepted. But $\mathrm{HH}$ alone cannot singularly inhibit the influence of formidable risk factors for HAI. ${ }^{13}$ The HH behavior is complex and is influenced by numerous factors. ${ }^{14}$

\section{Conclusion}

It could be concluded that $\mathrm{HH}$ compliance was associated with the decrease in HAIs. HH could be a simple and cost-effective method in prevention of HAIs. These studies can be done without any funding but with great effect to the health-care setup.

\section{Conflict of Interest}

None.

\section{Acknowledgment}

We are thankful to our nursing staff, laboratory staff, and fellow doctors for their cooperation and support.

\section{References}

1 Pittet D. Hand Hygiene in Health Care First Global Patient Safety Challenge Clean Care is Safer Care. World Health 2009;30(1):270, Available from http://whqlibdoc.who. int/publications/2009/9789241597906_eng.pdf [Internet]

2 Pittet D, Allegranzi B, Sax H, et al. WHO Global Patient Safety Challenge, World Alliance for Patient Safety. Evidence-based model for hand transmission during patient care and the role of improved practices. Lancet Infect Dis 2006;6(10):641-652

3 Ehrenkranz NJ, Alfonso BC. Failure of bland soap handwash to prevent hand transfer of patient bacteria to urethral catheters. Infect Control Hosp Epidemiol 1991;12(11):654-662

4 Sanderson PJ, Weissler S. Recovery of coliforms from the hands of nurses and patients: activities leading to contamination. J Hosp Infect 1992;21(2):85-93

5 Riggs MM, Sethi AK, Zabarsky TF, Eckstein EC, Jump RLP, Donskey CJ. Asymptomatic carriers are a potential source for transmission of epidemic and nonepidemic Clostridium difficile strains among long-term care facility residents. Clin Infect Dis 2007;45(8):992-998

6 Ofner-Agostini M, Gravel D, McDonald LC, et al. Cluster of cases of severe acute respiratory syndrome among Toronto healthcare workers after implementation of infection control precautions: a case series. Infect Control Hosp Epidemiol 2006;27(5):473-478

7 Ho PL, Tang XP, Seto WH. SARS: Hospital infection control and admission strategies. Respirology 2003;8:S41-S45

8 CDC Use of influenza A (H1N1) 2009 monovalent vaccine. Available at: https://www.cdc.gov/mmwr/preview/ mmwrhtml/rr58e0821a1.htm Accessed May 24, 2020

9 Chavali S, Menon V, Shukla U. Hand hygiene compliance among healthcare workers in an accredited tertiary care hospital. Indian J Crit Care Med 2014;18(10):689-693

10 Hoffmann M, Sendlhofer G, Gombotz V, et al. Hand hygiene compliance in intensive care units: an observational study. Int J Nurs Pract 2020;26(2):e12789, https://onlinelibrary.wiley. com/doi/abs/10.1111/ijn.12789 [Internet]

11 Sharma S, Sharma S, Puri S, Whig J. Hand hygiene compliance in the intensive care units of a tertiary care hospital. Indian J Community Med 2011;36(3):217-221

12 Salama MF, Jamal WY, Mousa HA, Al-Abdulghani KA, Rotimi VO. The effect of hand hygiene compliance on hospital-acquired infections in an ICU setting in a Kuwaiti teaching hospital. J Infect Public Health 2013;6(1): 27-3410.1016/j.jiph.2012.09.014[Internet]

13 McLaws ML. The relationship between hand hygiene and health care-associated infection: It's complicated. Infect Drug Resist 2015;8:7-18

14 Allegranzi B, Pittet D. Role of hand hygiene in healthcare-associated infection prevention. J Hosp Infect 2009;73(4):305-315 